\title{
Concentration and variability of ice nuclei in the subtropical maritime boundary layer
}

\author{
André Welti ${ }^{1}$, Konrad Müller ${ }^{1}$, Zoë L. Fleming ${ }^{2}$, and Frank Stratmann ${ }^{1}$ \\ ${ }^{1}$ Leibniz Institute for Tropospheric Research (TROPOS), Leipzig, Germany \\ ${ }^{2}$ National Centre for Atmospheric Science (NCAS), Department of Chemistry, University of Leicester, Leicester, UK
}

Correspondence: André Welti (welti@tropos.de)

Received: 22 August 2017 - Discussion started: 30 August 2017

Revised: 19 February 2018 - Accepted: 21 February 2018 - Published: 19 April 2018

\begin{abstract}
Measurements of the concentration and variability of ice nucleating particles in the subtropical maritime boundary layer are reported. Filter samples collected in Cabo Verde over the period 2009-2013 are analyzed with a drop freezing experiment with sensitivity to detect the few rare ice nuclei active at low supercooling. The data set is augmented with continuous flow diffusion chamber measurements at temperatures below $-24^{\circ} \mathrm{C}$ from a 2-month field campaign in Cabo Verde in 2016. The data set is used to address the following questions: what are typical concentrations of ice nucleating particles active at a certain temperature? What affects their concentration and where are their sources? Concentration of ice nucleating particles is found to increase exponentially by 7 orders of magnitude from -5 to $-38^{\circ} \mathrm{C}$. Sample-to-sample variation in the steepness of the increase indicates that particles of different origin, with different ice nucleation properties (size, composition), contribute to the ice nuclei concentration at different temperatures. The concentration of ice nuclei active at a specific temperature varies over a range of up to 4 orders of magnitude. The frequency with which a certain ice nuclei concentration is measured within this range is found to follow a lognormal distribution, which can be explained by random dilution during transport. To investigate the geographic origin of ice nuclei, source attribution of air masses from dispersion modeling is used to classify the data into seven typical conditions. While no source could be attributed to the ice nuclei active at temperatures higher than $-12^{\circ} \mathrm{C}$, concentrations at lower temperatures tend to be elevated in air masses originating from the Sahara.
\end{abstract}

\section{Introduction}

Ice crystals form in the atmosphere in a number of different ways. If ice formation is initiated by an ice nucleating substance immersed in a supercooled cloud droplet, the ice nucleation mechanism is referred to as immersion freezing. The effect immersion freezing exerts on clouds (cloud depth, lifetime, radiative properties and rain formation) depends on, besides updraft velocities and cloud-drop spectrum, the concentration of ice nuclei (IN) active at a particular temperature (Hallett and Mossop, 1974; DeMott et al., 2010).

Ambient measurements of IN concentrations from various studies were compiled by Fletcher (1962) to derive a spectrum of the average IN concentration as a function of temperature (curve shown in Fig. 1). Fletcher's curve has been found to match ice crystal concentrations measured in stratiform clouds and cold-based convective clouds but underpredict the concentration in deep convective clouds (e.g., Mossop, 1985; Cooper, 1986). Matching concentrations of ice crystals and IN indicate a direct influence of immersion freezing IN on cloud properties.

At what concentration ice crystals exert a substantial influence on the properties of the cloud in which they form, has been addressed by Rangno and Hobbs (1988). From aircraft and mountaintop observations, Rangno and Hobbs (1988) identified the significant ice crystal concentrations able to produce precipitation to be on the order of $1 \mathrm{~L}^{-1}$ or more; see Fig. 1. In their data set, such concentrations have been measured in cumulus clouds with top temperatures between -5 and $-10^{\circ} \mathrm{C}$. At this temperature, this is a much larger concentrations than expected from the Fletcher curve and indicates secondary ice formation. Secondary ice formation mechanisms (most efficient at $-5^{\circ} \mathrm{C}$ ) can increase the ice 
crystal concentration within a cloud by as much as 4 orders of magnitude above the number of IN present (e.g., Hallett and Mossop, 1974; Hobbs and Rangno, 1985; Mossop et al., 1970). Already few active IN $\left(0.01 \mathrm{~L}^{-1}\right)$ can be enough to start the multiplication (Sullivan et al., 2018). In situ evidence for secondary ice formation is reported in Hoffer and Braham (1962). They collected graupel from the top of cumulus clouds to melt and refreeze them under laboratory conditions. They found that every sample froze at substantially lower temperatures than the lowest temperature in the cloud from which they were collected, indicating that they did not contain IN active at the temperature the ice pellets froze in the cloud.

Typical temperatures at which ice crystals are observed to form in numbers high enough to affect the properties of clouds have been measured by remote sensing. Satellite observations, averaging clouds globally (e.g., Carro-Calvo et al., 2016) and ground-based lidar measurements, looking at shallow clouds (e.g., Ansmann et al., 2009), report that above $-10^{\circ} \mathrm{C}$ ice containing clouds are rarely detected and often cloud top temperatures below $-20^{\circ} \mathrm{C}$ are necessary for clouds to glaciate. Satellite data (Carro-Calvo et al., 2016; Rosenfeld et al., 2011) and aircraft observations (Rangno and Hobbs, 1991, 1994) agree on a land-sea contrast with the tendency of cloud glaciation at higher cloud top temperatures over sea. Carro-Calvo et al. (2016) offer the explanation that the presence of larger-sized droplets in maritime clouds, which are required for effective secondary ice formation (Heymsfield and Willis, 2014), could play a role. Hallett and Mossop (1974) suggested that marine cumuli contain large ice crystal concentrations for dynamical reasons. They usually have higher cloud top temperatures; therefore, the contact of ice and supercooled droplets occurs at temperatures favorable for splintering.

Several studies (e.g., Hobbs and Locatelli, 1970; Bertrand et al., 1973; Borys and Duce, 1979; Castro et al., 1998) observed that IN concentrations in maritime air masses are generally lower than in continental air, suggesting no important source for IN from the ocean. But Bigg (1961) and Soulage (1961) measured an increased IN concentration in air of maritime and coastal origin, providing directly conflicting evidence for the importance of the ocean as an IN source. More recently, laboratory investigations (DeMott et al., 2016; McCluskey et al., 2017), modeling (Burrows et al., 2013; Vergara-Temprado et al., 2017) and ambient observations (Wilson et al., 2015) showed that under certain conditions, IN from marine sources can be abundant enough to significantly contribute to the total IN population, particularly in high latitudes.

Two main sources for IN in maritime air have been proposed: long-range-transported continental aerosol (mainly dust) suggested by Bigg (1973) or marine organic ice nuclei of biogenic origin aerosolized with the sea spray (Schnell and Vali, 1975; Rosinski et al., 1987). Aerosol from both sources have been investigated (e.g., DeMott et al., 2003, 2016, and references therein). They found that marine-sourced IN are less efficient than IN from continental sources and can contribute IN in a broad temperature range. From laboratory experiments it is established that dust particles tend to nucleate ice efficiently below $-20^{\circ} \mathrm{C}$ whereas some biological substances can efficiently initiate immersion freezing at temperatures up to $-5^{\circ} \mathrm{C}$ (Murray et al., 2012). Joly et al. (2014) demonstrated that the particles initiating immersion freezing in cloud water samples collected at Puy de Dôme consist, to an increasing fraction, of biological IN (identified by susceptibility to heat treatment) towards higher freezing temperatures. They estimate $77 \%$ biological IN at $-12{ }^{\circ} \mathrm{C}$ increasing to $100 \%$ at $-8{ }^{\circ} \mathrm{C}$.

The different temperature range in which dust or biological particles act efficiently as IN can generate a specific signature in the concentration-temperature spectrum if there is a change in abundance (see also Sect. 4 and Appendix A). Some biological particles, and in particular bacterial IN of one source, tend to exhibit uniform ice nucleating properties. They initiate ice formation in a narrow temperature range seen as a step-like increase in concentration in a temperature spectrum (e.g., Murray et al., 2012). In contrast, dust particles activate in a broader temperature range (e.g., due to inhomogeneities in composition, surface structure and the influence of particle size on ice nucleation efficiency) seen as exponential increase in concentration towards lower temperatures (Bigg, 1961). If a strong marine source of biological origin exists it may be detectable as an inflection in IN concentration at temperatures above $-16^{\circ} \mathrm{C}$ where the ice nucleating fraction of dust particles is small.

The concentration of potential IN measured at a certain location and temperature can undergo large changes on timescales of days (Bigg, 1958) or hours (Bigg, 1961). This can be seen as indication that in terms of IN the atmosphere is poorly mixed. Pockets of high concentration can be followed by an almost IN-free period as air moves by the location of measurement. The two main factors influencing IN concentration and variability at a certain location are

1. the characteristics of the present population of aerosol particles (e.g., size distribution, composition);

2. transport processes (initial concentration of the IN at its source, location of the source relative to the sampling location, modification and dilution during transport; Anderson et al., 2003).

Membrane filter samples have been used to detect ice nuclei at low supercooling since the beginning of ambient IN concentration measurements (Bigg, 1961; Bigg et al., 1963). To measure the low concentration of IN, able to initiate immersion freezing above $-20^{\circ} \mathrm{C}$, it is necessary to collect particles from a large enough air volume. The time required to collect this volume depends on the sample flow through the filter, which is influenced by its type (fiber or membrane), fiber or pore size and the capacity of the pump. Long sam- 
pling times may be necessary. Some problems of long sample exposures were identified by Mossop and Thorndike (1966). The collected particles are subject to gas condensation or aging, or can be covered by aggregating smaller particles during sampling which could reduce the concentration of active IN. Daily integrated samples not only average out minor erratic fluctuations but also potential high count periods (e.g., due to the dissipation of the nocturnal inversion; Bigg, 1961) within the sampling time. Higher IN concentrations (up to 3 orders of magnitude; see Sect. 8) than the reported background concentration can be expected on timescales smaller than what is resolved by the used filter collection.

\section{Sampling site}

Samples are taken at the Cape Verde Atmospheric Observatory $\left(\mathrm{CVAO} ; 16.848^{\circ} \mathrm{N}, 24.871^{\circ} \mathrm{W}\right)$ strategically placed on the northeastern shore of São Vincente (one of the northern islands of the Cabo Verde archipelago). The Cabo Verde islands are located $16^{\circ} \mathrm{N}, 570 \mathrm{~km}$ off the coast of western Africa. Situated in the trade wind zone, the northeasterly winds prevail throughout the year, bringing in air masses from the open ocean. São Vincente is downwind of the coastal upwelling region on the western coast of Africa with high marine biological productivity and the outflow of the Sahara. Characteristic aerosol particles are of marine origin (e.g., sea spray) mixed with a continental background (mineral dust and smoke from biomass burning; Fomba et al., 2014). From December to February a strong Saharan dust period is typical. Filter samples are collected on a tower $30 \mathrm{~m}$ above the sea surface, $70 \mathrm{~m}$ from the coastline. The $30 \mathrm{~m}$ tower reaches out of the high sea salt loaded ground layer (Blanchard and Woodcock, 1980) into the mixed, maritime boundary layer.

\section{Experimental method}

Quartz fiber filters $(150 \mathrm{~mm})$, sampled using a Digitel filter sampler (DHA-80) with a PM $_{10}$ inlet, are used to obtain a time series of ice nuclei concentration with 24 to $72 \mathrm{~h}$ resolution. The $\mathrm{PM}_{10}$ inlet excludes particles $\geq 10 \mu \mathrm{m}$ from being sampled. To determine the IN concentration, 103 random subsamples, each containing aerosol from an air volume of $37-114 \mathrm{~L}$ are punched out of each filter, immersed in $100 \mu \mathrm{L}$ droplets inside $0.5 \mathrm{~mL}$ safe-lock tubes and subject to temperatures down to $-25^{\circ} \mathrm{C}$, allowing ice formation by immersion freezing. Freezing due to impurities in the water typically sets in below $-20^{\circ} \mathrm{C}$. Blank subsamples taken from filter through which no air was drawn start to cause freezing below $-16^{\circ} \mathrm{C}$. In $50 \%$ of the blank samples, the filter material does not initiate ice formation above $-20^{\circ} \mathrm{C}$. The drop freezing assay is set up following the description in Conen et al. (2012), with the difference that the circular subsamples used for the present measurements are only $1 \mathrm{~mm}$ in diame- ter. According to Vali (1971), the cumulative concentration of IN per air volume as a function of temperature $(K(\theta))$ can be calculated by

$K(\theta)=\left(\ln N_{0}-\ln N(\theta)\right) / V$,

with $N_{0}$ denoting the number of subsamples, $N(\theta)$ the number of unfrozen subsamples at temperature $\theta$ and $V$ the volume of air passed through each $1 \mathrm{~mm}$ subsample. With the given number of subsamples, their diameter and sampled air volume the method is sensitive to concentrations from approx. $0.08-130 \mathrm{IN} \mathrm{m}^{-3}$. Following Conen et al. (2012) the uncertainty ( 1 standard deviation) in measuring $K(\theta)$ is given by

$\mathrm{d} K(\theta)= \pm \sqrt{K(\theta)} /\left(N_{0} \cdot \sqrt{V}\right)$.

For clarity of presentation, data in the following figures are shown without the range of uncertainty given in Eq. (2).

During a field campaign in January-February 2016 concentration measurements of IN active at low temperatures were conducted using the SPectrometer for Ice Nuclei (SPIN). SPIN is a parallel plate continuous flow diffusion chamber designed based on the chamber discussed in Stetzer et al. (2008). Aerosol was sampled at a flow rate of $1 \mathrm{~L} \mathrm{~min}^{-1}$ through an inlet up on the same $30 \mathrm{~m}$ high tower where the $\mathrm{PM}_{10}$ filter sampler was located. An impactor (TSI, $0.071 \mathrm{~cm}$ orifice) was used to limit the particle size sampled with SPIN. For details on the SPIN instrument we refer to the description in Garimella et al. (2016).

\section{Temperature spectra of cumulative ice nuclei concentration}

The temperature spectra (Fig. 1) summarize data from 500 analyzed filter samples which were collected from 2009 to 2013 at the CVAO. Data in red, green and blue represent measurements at $-8,-12$ and $-16^{\circ} \mathrm{C}$. These data are shown in the same colors in Figs. 2, 3, 4, 5, B1, and C1. The $30 \mathrm{~min}$ average concentrations measured with SPIN during the intense campaign in 2016 complement the data set in the temperature range from $-24{ }^{\circ} \mathrm{C}$ to the onset of homogeneous freezing below $-38^{\circ} \mathrm{C}$. The range of measured IN concentrations at constant temperature is large. Measurements vary up to 3 orders of magnitude for the 24 to $72 \mathrm{~h}$ filter samples and cover up to 4 orders of magnitude in the $30 \mathrm{~min}$ SPIN data. For the filter data, the temperature-dependent change in concentration is similar to the slope of the approximation proposed in Fletcher (1962), indicated in Fig. 1. Concentrations measured with SPIN at lower temperatures show a weaker temperature dependence, vary in a larger range and diverge from the Fletcher approximation (see Fig. 1).

It seems to be indistinguishable whether there are a few particles with a high probability to act as IN or many, less active aerosol particles representing the concentration of IN 


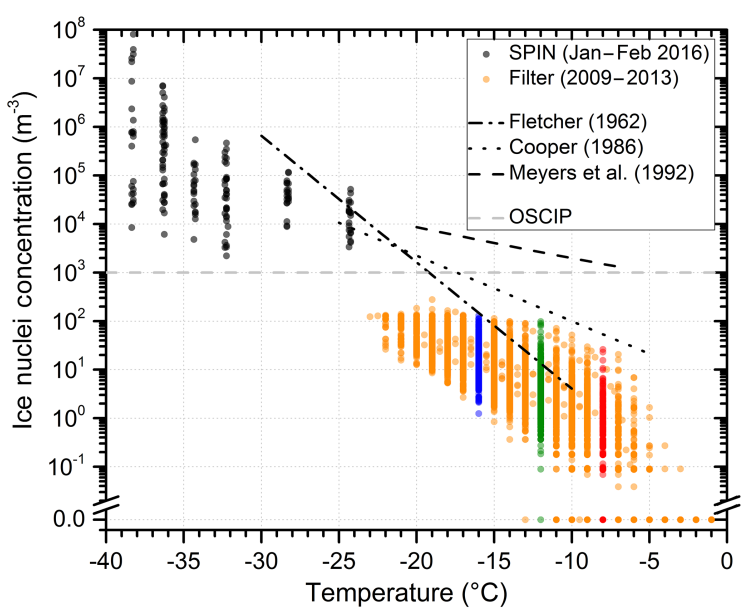

Figure 1. Cumulative ice nuclei concentration as function of temperature. Date and method of measurement are indicated in the figure. Filter data at $-8,-12$ and $-16^{\circ} \mathrm{C}$ are color-coded red, green and blue. These data are shown in the same colors in subsequent figures. Parametrizations from Fletcher (1962), Cooper (1986) and Meyers et al. (1992) are given for comparison. All parametrizations are shown in their valid temperature range. The OSCIP (Onset of Significant Concentrations of Ice Particles; Rangno and Hobbs, 1988) provides a guideline concentration for effecting cloud properties by primary ice nucleation.

at a certain temperature. From the cumulative temperature spectra, it can be argued that the former is the case. Assuming that IN of certain size and composition develop their ice nucleation activity in a narrow temperature range, a low activated fraction of an abundant IN at one temperature would generate a steep increase in concentration with decreasing temperature (see Appendix A for an extended discussion on the interpretation of IN temperature spectra). Concentrations measured at CVAO are observed to increase exponentially from -5 to $-38^{\circ} \mathrm{C}$, indicating a broad variety of particle properties (e.g., size, composition, ice active surface sites) responsible for ice formation at different temperatures.

The temperature-dependent increase in concentration (slope of the temperature spectrum) is not constant for different filters, indicating active IN of varying nature and abundance that contribute to the temperature spectra at different occasions. For additional discussion of the variability in slopes we refer to Bigg (1961) and Appendix A. Assuming that particles make a significant contribution to the temperature spectrum only in the temperature range where their ice nucleation activity is high (Appendix A), scattering in the IN concentration at a temperature $\theta$ can be explained by the variation in the concentration of particles with a certain property. If the properties of IN active at a certain temperature, and therefore measured IN concentrations are correlated with bulk chemical aerosol composition or air mass origin is analyzed in Sects. 6 and 7.

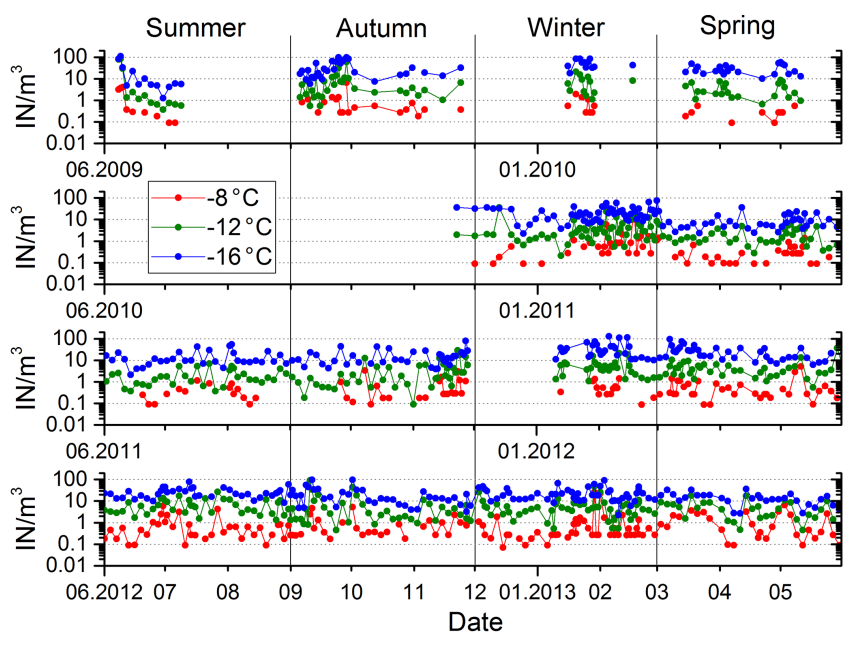

Figure 2. Four-year time series of ice nuclei concentration at three temperatures indicated in the figure.

\section{Time series}

The variation of ice nuclei concentration with time is exemplified by data at $-8,-12$ and $-16^{\circ} \mathrm{C}$ in Fig. 2 . The 4 years during which filter samples were collected represent a cross section of the different atmospheric conditions (dust events, rain, dry tropical) encountered in Cabo Verde. Neglecting extreme values, IN concentration is changing within 2 orders of magnitude, without obvious cycles in the series. The measurement in the time series are positively first-order autocorrelated for all temperatures between -6 and $-16^{\circ} \mathrm{C}$, i.e., persistence in above-/below-average IN concentration on consecutive filter samples. Concentrations measured on samples further apart are not autocorrelated. Variations in IN concentration are non-synchronous at different temperatures (see Fig. 2), indicating differences in origin of the ice nuclei populations active at different temperatures. This observation is analog to the change in slope of the temperature spectra for different filter samples discussed in Sect. 4. With increasing difference in temperature, the variation in IN concentration at two temperatures become less correlated $\left(R^{2}=0.30\right.$, $R^{2}=0.37, R^{2}=0.09$ for -8 to $-12,-12$ to $-16,-8$ to $\left.-16^{\circ} \mathrm{C}\right)$. The time series shows no distinct seasonal or interannual trends during the 4 years of measurements (see Appendix $\mathrm{B}$ for an interannual comparison of season-separated IN concentrations).

\section{Bulk chemical composition}

The 24 to $72 \mathrm{~h}$ filter samples were used to analyze the bulk chemical composition of the collected aerosol. Methods and details of the chemical analysis can be found in Fomba et al. (2014), where the results of the chemical analysis from samples collected between 2007 and 2011 at CVAO are presented. Besides the derivation of the $\mathrm{PM}_{10}$ aerosol mass, the 

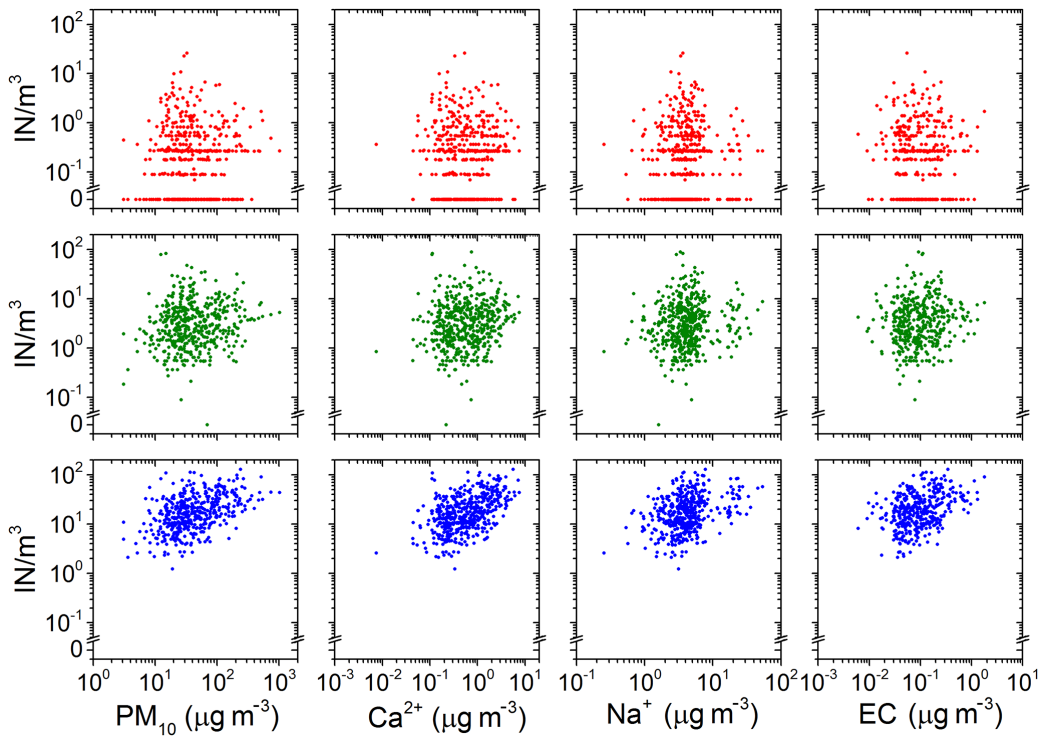

Figure 3. Relation between the concentration of IN at $-8{ }^{\circ} \mathrm{C}$ (red), $-12{ }^{\circ} \mathrm{C}$ (green), $-16{ }^{\circ} \mathrm{C}$ (blue) and total particle mass concentration, mass concentrations of calcium $\left(\mathrm{Ca}^{2+}\right)$, mass concentration of sodium $\left(\mathrm{Na}^{+}\right)$and mass concentration of elemental carbon $(\mathrm{EC}) . \mathrm{Ca}^{2+}, \mathrm{Na}^{+}$ and EC are tracers of continental, marine and combustion sources, respectively.

chemical analysis included ion mass concentrations of $\mathrm{Na}^{+}$, $\mathrm{NH}_{4}^{+}, \mathrm{K}^{+}, \mathrm{Mg}^{2+}, \mathrm{Ca}^{2+}, \mathrm{Cl}^{-}, \mathrm{Br}^{-}, \mathrm{NO}_{3}^{-}, \mathrm{SO}_{4}^{2-}, \mathrm{C}_{2} \mathrm{O}_{4}^{2-}$, organic (OC) and elemental carbon (EC).

The sampling time allows for resolving aerosol mass concentration and composition on a synoptic scale (on the order of $1000 \mathrm{~km}$ ). It is assumed in this sampling strategy that aerosol composition mainly changes with horizontal changes in air masses (e.g., frontal systems) that occur on this scale. Additionally, variation in bulk aerosol mass concentration and composition on the synoptic scale can often be related to sources via back trajectories (Anderson et al., 2003). If IN sources were related to the sources of bulk chemical components, they could be used as a tracer to identify source region or aerosol constituents contributing to the IN population. Figure 3 shows scatter plots of IN concentration at $-8,-12$ and $-16^{\circ} \mathrm{C}$ versus $\mathrm{PM}_{10}$ as a tracer for desert dust and concentrations of $\mathrm{Ca}^{2+}, \mathrm{Na}^{+}, \mathrm{EC}$ as indicators of continental, maritime and combustion sources. Except an insignificant tendency $\left(R^{2}=0.11, R^{2}=0.17\right)$ of higher IN concentrations at $-16{ }^{\circ} \mathrm{C}$ towards higher $\mathrm{PM}_{10}$ and $\mathrm{Ca}^{2+}$ mass concentration, the scattering is uncorrelated. Using Spearman statistics, monotonic association (more is more, or more is less) between the IN concentration at temperatures from -5 to $-16^{\circ} \mathrm{C}$ and mass concentration of all chemical components is tested. No significant correlation exists. While the IN concentration at temperatures above $-16^{\circ} \mathrm{C}$ is not correlated with the amount of continental aerosol, evidence for the importance of the Sahara as source of IN at lower temperatures is found in the analysis of air mass origin (Sect. 7). This apparent contradiction can be explained as a non-constant ice active fraction in the Saharan dust aerosol transported to
Cabo Verde. A variable ratio of dust to IN concentration has previously been observed by Bertrand et al. (1973), who took measurements in western Africa. A comparison of IN concentration to the abundance of aerosol particles larger than a certain size can be found in Appendix C.

\section{Effect of air mass origin}

The origin of the air mass collected on the filters from 2009 to 2013 is determined using the NAME dispersion model (Jones et al., 2007) and classified into seven categories (as shown in Carpenter et al., 2010). NAME dispersion footprints are calculated for the air arriving at the site, showing where the air masses had been in the surface layer $(0-100 \mathrm{~m})$ in the previous 10 days. For each footprint, the proportional residence time in each geographical region (Atlantic, North America, Europe, coastal Africa and northern Africa) is used to classify each period into one of the seven air mass categories as shown in Fig. 4. Concentrations measured under the different categories at $-8,-12$ and $-16^{\circ} \mathrm{C}$ are shown as box plots in Fig. 4. Slightly elevated concentrations are found for dust- (from the Saharan and Sahel region) and Europeaninfluenced air mass. The influence of dust on IN concentration increases towards lower temperatures, where more dust minerals become ice active. Although air mass origin is correlated with season (dust storm season from December to February), no seasonal trend in IN concentration is found. It is unclear which ice active aerosol is contributed by Europe. It could be of industrial or agricultural origin. From the comparison of the seven conditions categorized in Fig. 4 it is seen that continental-affected air masses contain higher IN 


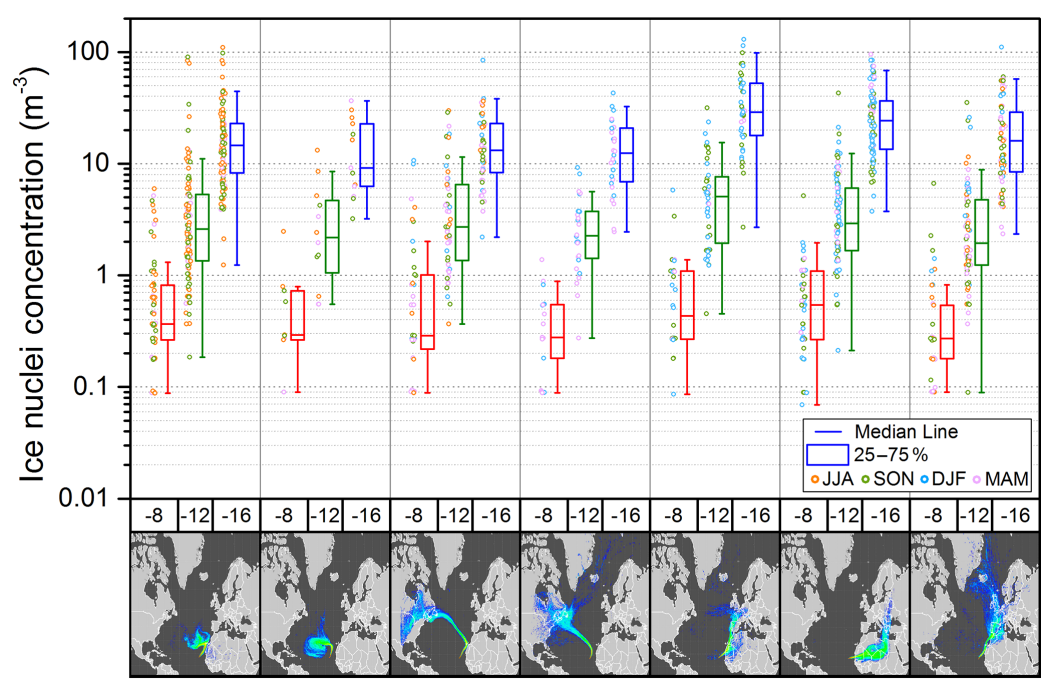

Figure 4. Variation of ice nuclei concentration classified into seven conditions of air mass origin at three temperatures. Data shown to the left of each box plot is color-coded by season (JJA: June-August; SON: September-November; DJF: December-February; MAM: MarchMay). Air mass classification from left to right: (1) African coastal, (2) Atlantic marine, (3) North American, marine and coastal, (4) North American and marine, (5) dust and European, (6) dust (e.g., Saharan and Sahel region) and (7) coastal and European.

concentrations than pure maritime air mass. Vice versa, even though the location of measurement is in vicinity to high primary oceanic productivity no correlation of high IN concentration with coastal and marine air mass has been found in the temperature range accessible by the drop freezing method.

\section{Frequency distribution}

The IN concentration and variability measured at one location depends on the nature of the IN sources (strength and ice nucleation efficiency) and modification during transport (aging and dilution). While the cumulative temperature spectra (discussed in Sect. 4) can provide information on the efficiency and abundance of IN, the frequency distribution can be used to investigate the effect of transport.

It is found that lognormal frequency distributions best approximate the measured variability in concentrations at each individual temperature (see Fig. 5). The suitability of a lognormal distribution to approximate IN concentration frequency distributions has been recognized previously by Maruyama (1961), Isaac and Douglas (1971) and Radke et al. (1976). Isaac and Douglas (1971) demonstrated that the frequency distribution of IN concentration does not follow a Poisson distribution, thereby proving that IN are not randomly distributed in the atmosphere.

An explanation for the lognormal frequency distribution in concentration (such is also often found in concentrations of ambient pollution) has been given by the theory of successive random dilutions (Ott, 1990). A lognormal distribution indicates that the initial IN concentration at the source has undergone a series of random dilutions while being transported. In the case of IN concentration where ice nucleating particles are lofted from the surface and transported in the free atmosphere to the measurement site, turbulent mixing randomly dilutes the initial concentration. Variation in source strength (e.g., particle concentration) does not change the lognormal standard deviation of the distribution, but causes a shift in concentrations. Only proximity of the measurement location to the IN source, and thus the maximum concentration possible (no dilution) would cause an even more skewed frequency distribution with a stronger downward bend at high concentrations (Ott, 1990). Neither the frequency distribution obtained from filter measurements nor the measurements with SPIN show this feature. The unimodal, regular bell shape of the frequency distribution on the log scale indicates the absence of a strong local source. Measured concentrations can therefore be assumed to represent the background concentration in a subtropical maritime environment defined by long-range transport.

\section{Discussion}

The comparison of IN concentrations from filter samples to chemical bulk aerosol composition did not allow identification of the nature or source of IN active at low supercooling. Potentially important particle classes are mineral dusts and biological particles advected with dust or from marine sources. Based on laboratory measurements of the ice nucleation efficiency of Saharan dust from the Hoggar region, Pinti et al. (2012) suggested that during dust events sufficient dust IN active between -13 and $-23^{\circ} \mathrm{C}$ could be present at Cabo Verde to initiate cloud glaciation. Classification of 


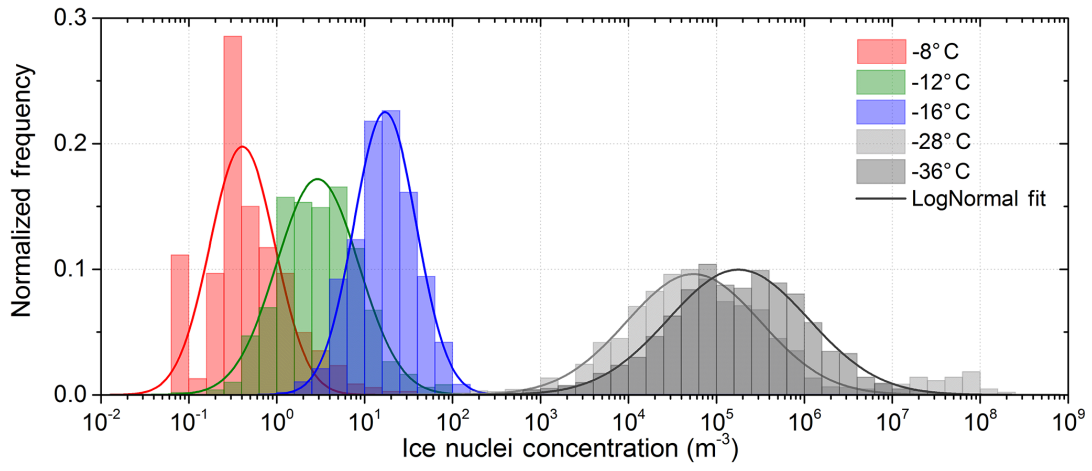

Figure 5. Frequency distribution of measured IN concentration with lognormal fit curves.

source regions into seven prevalent conditions supports the importance of continental IN by showing slightly elevated median IN concentrations during continental air mass conditions.

From lidar observations discussed in Ansmann et al. (2009) it is known that generally temperatures need to drop below $-20^{\circ} \mathrm{C}$ for glaciation to be detected in altocumulus clouds (altitude $7 \mathrm{~km}$ ) over Cabo Verde. Cases when clouds glaciated at higher temperatures, between -5 and $-20^{\circ} \mathrm{C}$, could often be attributed to seeding of the supercooled cloud with ice crystals from clouds at higher altitude. The present measurements of potential IN concentrations at ground level indicate that glaciation can start at higher temperatures, but OSCIP (indicated in Fig. 1) would typically be reached at $-20^{\circ} \mathrm{C}$.

The main challenge to identifying the composition or source of IN by correlating concentration measurements with information on bulk chemical composition is the small fraction of IN in all particles. Only when an IN source contributes an unusually large fraction to the aerosol, e.g., during a dust storm (Boose et al., 2016) or downwind of a forest fire (McCluskey et al., 2014), can bulk chemical composition corroborate the IN source. Efforts to pinpoint the contributions from specific sources should focus on measuring close to the source or investigating collected samples from single sources under laboratory conditions.

No evidence was found that the ocean is a general source for high IN concentration in the subtropics. This confirms observations by, for example, Isono et al. (1959), Carte and Mossop (1960) and Hobbs and Locatelli (1970) that IN concentrations in air masses with a purely maritime trajectory tend to be low. Ice nucleating particles that originate from sea water and are active at low supercooling (Schnell and Vali, 1975; DeMott et al., 2016) might be airborne at too low concentrations and in general only constitute a minor source to background concentrations. However, low IN concentrations do not necessarily indicate low ice crystal numbers in developed clouds if conditions favor secondary ice multiplication mechanisms. Also, in particular circumstances (e.g., algae bloom) the purely marine IN could be of regional im- portance. Burrows et al. (2013) and Vergara-Temprado et al. (2017) suggest strong regional differences in the importance of marine biogenic and dust IN, with the highest impact of marine IN on cloud properties in the remote Southern Ocean far from strong dust sources.

Filter samples are collected on timescales of 1- to 3-day sampling time, resolving variations on a synoptic scale (order of $1000 \mathrm{~km}$, typical for frontal systems). The sampling strategy is chosen based on the assumption that concentration and composition of aerosol are constant within the horizontal scale of the air mass passing the sampling spot in this time interval (Anderson et al., 2003). Using filter samples originally collected for monitoring the aerosol composition therefore provides insight into the variation and concentration of IN on a synoptic scale. The sampled air volume and the drop freezing method confine the sensitivity of the measurement to the rare IN active at low supercooling. Consequently the present time series obtained from filter samples gives information on the variation and concentration of highly active IN on a synoptic scale. From SPIN measurements (see Fig. 5) using a sampling time of $10 \mathrm{~s}$ (corresponding to a scale on the order of $100 \mathrm{~m}$ ), high variability within the synoptic scale is observed. Although SPIN measurements are at lower temperatures where different particle types contribute to the IN population, the variability of rare IN counts, if it could be observed at high temporal resolution, could be on the same order as the variation in low temperature IN concentration. Only by the extent of the filter time series does the variability range approach the range observed in the much shorter time domain. This highlights the need to collect large enough (long time series or high frequency) data sets to characterize variability and correlation with aerosol properties.

\section{Conclusions}

Typical IN concentrations in the subtropical marine environment are obtained from 500 particle filter samples collected over 4 years and from a 2-month field campaign with the SPIN instrument. Concentrations increase exponentially 
from $10^{-1}$ to $10^{6} \mathrm{~m}^{-3}$ from -5 to $-38^{\circ} \mathrm{C}$. Over time, the concentration varies up to 3 orders of magnitude on a synoptic scale (filter samples) and up to 4 orders of magnitude on a higher resolution (SPIN measurements). The frequency with which certain concentrations are measured at a temperature $\theta$ follows a lognormal distribution, characteristic for successive random dilution during long-range transport. The lognormal frequency distribution is found at all investigated temperatures. Parametrizations in numerical models should reproduce this feature.

For the long-term series of filter measurements, we find that random dilution during transport could account for larger fluctuations in IN concentration than seasonal changes, changes in air mass origin and changes in the bulk aerosol composition. At Cabo Verde, the latter do not reveal a clear correlation with the measured IN concentration. The only observable tendency is that continental air masses contain higher IN concentrations than maritime air masses, in agreement with previous measurements (e.g., Bertrand et al., 1973) and model predictions (e.g., Burrows et al., 2013). The absence of an annual trend despite a dust and a biological active season is surprising and highlights the lack of knowledge about the nature of ice nucleating particles in this environment.

The diversity of the ice nuclei population manifests in the shape of the cumulative temperature spectra. The contribution of each source to the temperature spectra depends on the source strength, dilution during transport and the temperature range to which the source contributes efficient IN. Multiple sources, together with random dilution, could produce the appearance of a ubiquitous, almost constant background concentration of IN.
Assuming $10^{3} \mathrm{~m}^{-3}$ to be the threshold IN concentration needed for a significant, primary effect on properties of supercooled clouds, temperatures below the range covered by the drop freezing experiment used in this study need to be reached to have an effect. If the temperature-dependent IN concentration exponentially increases with the slope of the Fletcher (1962) approximation, a primary effect of ice nucleation by immersion freezing on cloud glaciation and precipitation formation can be expected at $-20 \pm 5{ }^{\circ} \mathrm{C}$, matching the $-20^{\circ} \mathrm{C}$ alto cumulus cloud glaciation temperature over Cabo Verde reported by Ansmann et al. (2009). The SPIN data measured at temperatures below $-24{ }^{\circ} \mathrm{C}$ support the temperature trend. Assuming that measurements of IN concentrations at ground are representative of higher altitudes, the observation of cloud glaciation at $-20^{\circ} \mathrm{C}$ where IN concentrations reach OSCIP supports the importance of immersion freezing in affecting cloud properties in a subtropical marine environment.

Data availability. Data are available at https://doi.org/10.1594/ PANGAEA.887029 (Welti et al., 2018). 


\section{Appendix A: Components and features of cumulative temperature spectra}

Four example temperature spectra, produced using classical nucleation theory to describe immersion freezing are shown in Fig. A1. A contact angle distribution ( $\alpha$ pdf; see e.g., Welti et al., 2012) emulates the variation of ice nucleation efficiencies within a macroscopic homogeneous (size, composition) population of particles. The particle size distribution helps describe the effects of different surface areas within a particle population of the same material. Comparing the four panels in Fig. A1a, it can be seen that the effect of a contact angle distribution on flattening the slope of the frozen fraction (FF) is stronger than particle size variation.

In the following we explore typical features found in temperature spectra. We refer to IN species with the same frozen fraction curve as IN group. The number of IN in an IN group scaled with its temperature-dependent FF determines the IN concentration a group contributes to the temperature spectrum. The number of IN as a function of temperature, i.e., the cumulative temperature spectrum of an ambient measurement, consists of the IN concentration from several IN groups with partly overlapping activation temperatures (temperature where $0<\mathrm{FF}>1$ ).

Several IN groups can sum up to an almost smooth exponential temperature spectrum with no inflections (bumps). In this case the points of inflection in the frozen fraction of individual IN groups $(\mathrm{FF}=0.5)$ construct the slope of the spectrum (see Fig. A1b). Average freezing temperatures $\left(T_{50}\right)$ of $\mathrm{FF}=0.5$ reported in laboratory studies are therefore a wellsuited measure for transferring these results to ambient ice nucleation.
Fluctuations in the number of IN in different IN groups (e.g., due to advection of incompletely mixed air parcels with different IN content; Bigg and Hopwood, 1963) lead to a variation in the slope of the temperature spectrum or cause a bump (see below). A multitude of temperature spectra make the spread in observed IN concentration seen in Fig. 1; the frequency distribution is shown in Fig. 5.

Temperature spectra with bumps, from the combination of four IN groups, are shown as orange lines in Fig. A1b. The more narrow the IN properties of an IN group, the steeper the increase in FF and the more step-like it appears in a temperature spectrum. A broader distribution of IN properties decreases the slope. High concentration of a single IN group would emerge as a step-like peak over the other contributions. Note that a combination of four IN groups with broad distributions of IN properties suffices for approximating an exponential temperature spectrum.

Additional discussion of temperature spectra can be found in Bigg (1961), Bigg and Hopwood (1963), Fletcher (1962) and Vali (1971).

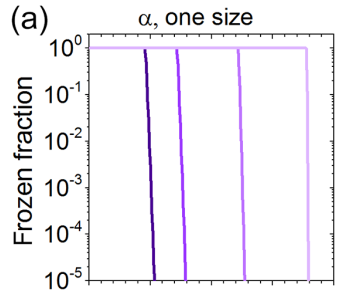

(b)

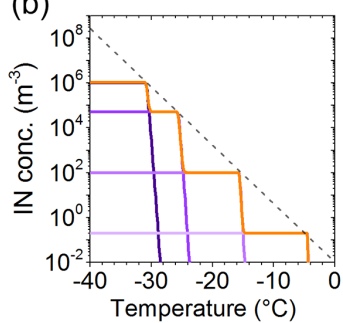

$\alpha$-pdf, one size
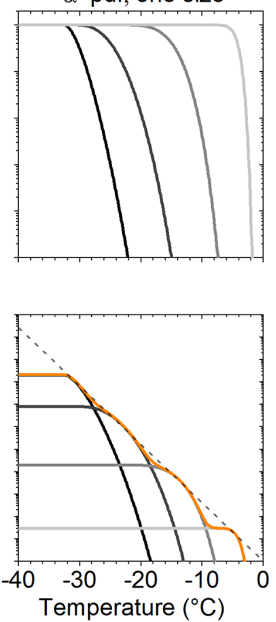
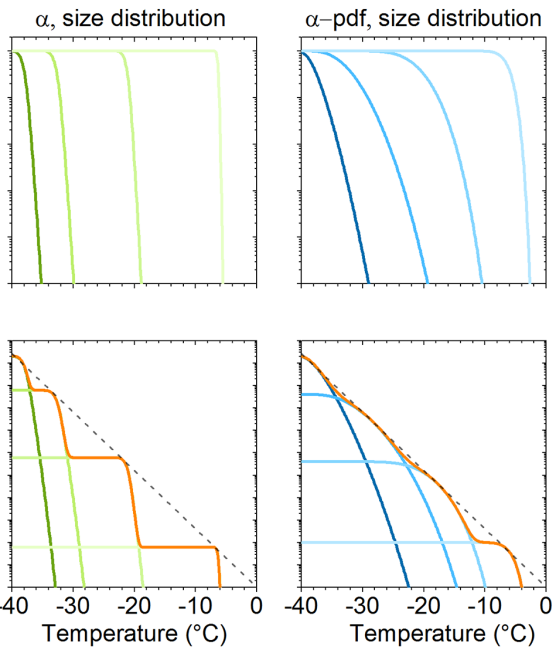

Figure A1. Illustration of the framework of the cumulative temperature spectrum. Each panel in (a) shows frozen fraction curves of four IN groups with $120,90,60$, and $30^{\circ}$ mean contact angles $(\alpha)$. Above the panels, variations in contact angle and particle size distribution within the IN groups are indicated. A normal distribution of contact angles (with $\mu=\alpha, \sigma=6^{\circ}$ ) and a lognormal particle size distribution are used to visualize the effect of variability within the four IN groups. Panel (b) shows scaling of frozen fraction with IN concentrations per group chosen, so curves follow the exponential parametrization of Fletcher (1962). 


\section{Appendix B: Seasonal variation of IN concentration}

Figure $\mathrm{B} 1$ shows the range of seasonal and interannual variation in IN concentration during the measurement period. Although air mass origin is correlated with season (dust storm season from December to February; see Fig. 4), no seasonal trends are found. Interannual variability within seasons is small during the 4 years of measurements. Rainy season and season of high biological productivity do not affect the measured range of IN concentration.
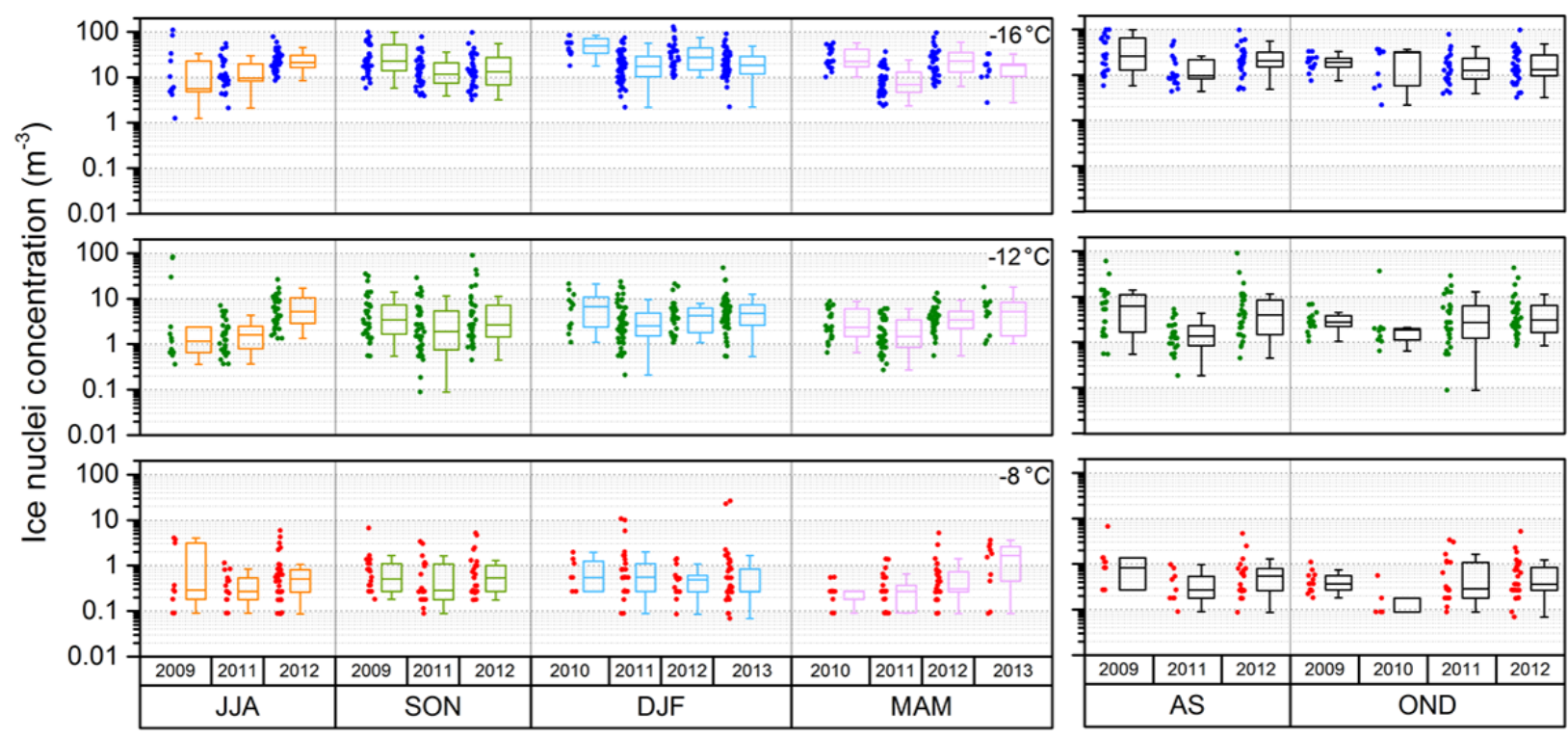

Figure B1. Seasonal variation in ice nuclei concentration separated for each year of measurement (JJA: June-August; SON: SeptemberNovember; DJF: December-February; MAM: March-May). Box plots of the rainy season (AS: August-September) and the season of high biological productivity (OND: October-December). 


\section{Appendix C: Comparison of IN concentration to number concentration of aerosol particles with diameters larger than $0.1,0.5,1 \mu \mathrm{m}$}

IN data in Fig. C1a at $-8,-12,-16^{\circ} \mathrm{C}$ are from filter measurements. IN concentrations shown in Fig. C1b at -28 , $-32,-36{ }^{\circ} \mathrm{C}$ are measured using SPIN. The comparison is made for concentration of particles with diameters larger than $0.1,0.5,1 \mu \mathrm{m}$. IN concentrations calculated according to the DeMott et al. (2010) parametrization, which connects the concentration of aerosol particles above a threshold size to IN concentration, roughly match the range of SPIN data in Fig. C1b, within 1 order of magnitude. Discrepancy is largest for low particle concentrations. IN concentrations from filter measurements are systematically lower than predicted by the parametrization. Note that the predicted concentration lies above the range of sensitivity of the filter method used in this study. Correlation of IN concentration to the concentration of particles larger than a certain size is higher for 0.5 and $1 \mu \mathrm{m}$ than for $0.1 \mu \mathrm{m}$. None of the correlations are significant. (a)
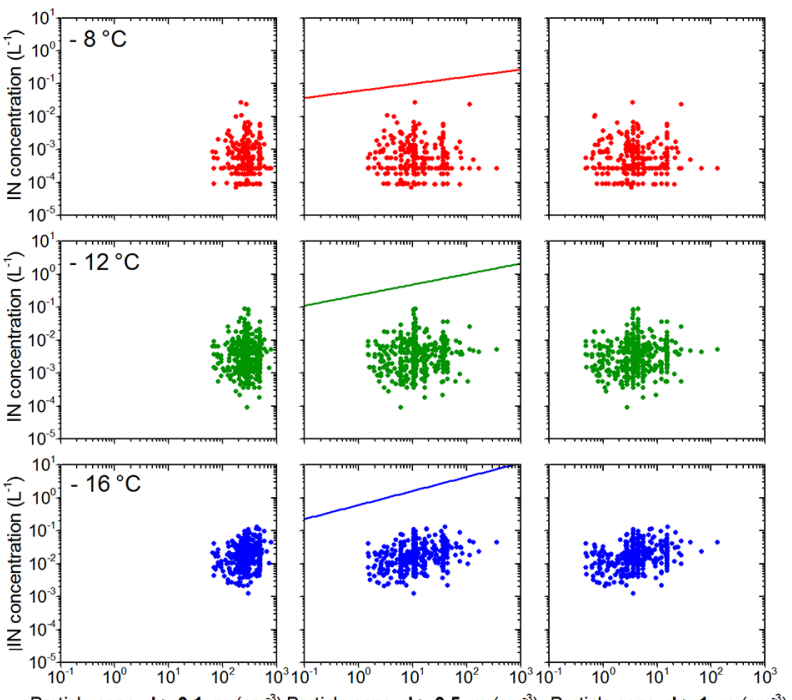

(b)
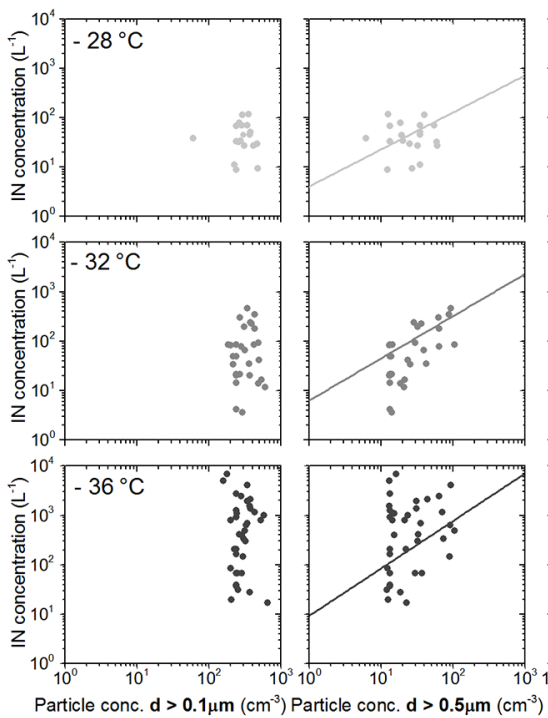
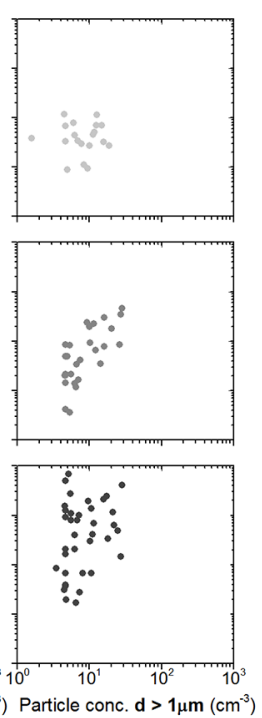

Figure C1. (a) The 24 to $72 \mathrm{~h}$ average IN concentration from filter experiments on the $y$ axis versus the total concentration of particles with diameters larger than $0.1,0.5,1 \mu \mathrm{m}$ on the $x$ axis; (b) 30 min average IN concentration from SPIN experiments versus the total concentration of particles larger than $0.1,0.5,1 \mu \mathrm{m}$. IN concentration predicted by the DeMott et al. (2010) parametrization is given in the center row of both panels. 
Competing interests. The authors declare that they have no conflict of interest.

Special issue statement. This article is part of the special issue "BACCHUS - Impact of Biogenic versus Anthropogenic emissions on Clouds and Climate: towards a Holistic UnderStanding (ACP/AMT/GMD inter-journal SI)". It is not associated with a conference.

Acknowledgements. We acknowledge financial support from the European Union's Seventh Framework Programme (FP7/20072013) project BACCHUS under grant agreement no. 603445. We would like to thank the UK Met Office for use of the NAME dispersion model and the STFC JASMIN supercomputer for hosting the model. Collection of filters at CVAO was made possible thanks to support by the German BMBF within the SOPRAN I and II projects (FKZ: 03F0462J and 03F0611J). Élise Beaudin, Nadja Samtleben, Lisanne Hölting, Mareike Löffler and Pit Strehl were principally responsible for preparation and conducting the filter sample experiments. Thomas Müller provided particle size distribution measurements from CVAO.

Edited by: Allan Bertram

Reviewed by: Keith Bigg

\section{References}

Anderson, T., Charlson, R., Winker, D., Ogren, J., and Holmén, K.: Mesoscale variations of tropospheric aerosols, J. Atmos. Sci., 60, 119-136, 2003.

Ansmann, A., Tesche, M., Seifert, P., Althausen, D., Engelmann, R., Fruntke, J., Wandinger, U., Mattis, I., and Müller, D.: Evolution of the ice phase in tropical altocumulus: SAMUM lidar observations over Cape Verde, J. Geophys. Res., 114, D17208, https://doi.org/10.1029/2008JD011659, 2009.

Bertrand, J., Baudet, J., and Dessens, J.: Seasonal Variations and Frequency Distribution of Ice Nuclei Concentrations at Abidjan, West Africa, J. Appl. Meteorol., 12, 1191-1195, 1973.

Bigg, E.: Natural Atmospheric ice nucle, Sci. Prog., 49, 458-475, 1961.

Bigg, E.: Ice Nucleus Concentration in Remote Areas, J. Atmos. Sci., 30, 1153-1157, 1973.

Bigg, E. and Hopwood, S.: Ice nuclei in the Antarctic, J. Atmos. Sci., 20, 185-188, 1963.

Bigg, E. K.: A long period fluctuation in freezing nucleus concentrations, J. Meteorol., 15, 561-562, 1958.

Bigg, E. K., Mossop, S. C., Meade, R. T., and Thorndike, N. S. C.: The Measurement of Ice Nucleus Concentrations by Means of Millipore Filters, J. Appl. Meteorol., 2, 266-269, https://doi.org/10.1175/15200450(1963)002<0266:TMOINC>2.0.CO;2, 1963.

Blanchard, D. and Woodcock, A.: The production concentration and vertical distribution of the sea-salt aerosol, Ann. N.Y. Acad. Sci., 338, 330-347, 1980.

Boose, Y., Sierau, B., García, M. I., Rodríguez, S., Alastuey, A., Linke, C., Schnaiter, M., Kupiszewski, P., Kanji, Z.
A., and Lohmann, U.: Ice nucleating particles in the Saharan Air Layer, Atmos. Chem. Phys., 16, 9067-9087, https://doi.org/10.5194/acp-16-9067-2016, 2016.

Borys, R. and Duce, R.: Relationship among Lead, Iodine, Trace Metals and Ice Nuclei in a Coastal Urban Atmosphere, J. Appl. Meteorol., 18, 1490-1494, 1979.

Burrows, S. M., Hoose, C., Pöschl, U., and Lawrence, M. G.: Ice nuclei in marine air: biogenic particles or dust?, Atmos. Chem. Phys., 13, 245-267, https://doi.org/10.5194/acp-13-2452013, 2013.

Carpenter, L. J., Fleming, Z. L., Read, K. A., Lee, J. D., Moller, S. J., Hopkins, J. R., Purvis, R. M., Lewis, A. C., Müller, K., Heinold, B., Herrmann, H., Fomba, K. W., van Pinxteren, D., Müller, C., Tegen, I., Wiedensohler, A., Müller, T., Niedermeier, N., Achterberg, E. P., Patey, M. D., Kozlova, E. A., Heimann, M., Heard, D. E., Plane, J. M. C., Mahajan, A., Oetjen, H., Ingham, T., Stone, D., Whalley, L. K., Evans, M. J., Pilling, M. J., Leigh, R. J., Monks, P. S., Karunaharan, A., Vaughan, S., Arnold, S. R., Tschritter, J., Pöhler, D., Frieß, U., Holla, R., Mendes, L. M., Lopez, H., Faria, B., Manning, A. J., and Wallace, D. W. R.: Seasonal characteristics of tropical marine boundary layer air measured at the Cape Verde Atmospheric Observatory, J. Atmos. Chem., 67, 87-140, https://doi.org/10.1007/s10874-011-9206-1, 2010.

Carro-Calvo, L., Hoose, C., Stengel, M., and SalcedoSanz, S.: Cloud glaciation temperature estimation from passive remote sensing data with evolutionary computing, J. Geophys. Res.-Atmos., 121, 13591-13608, https://doi.org/10.1002/2016JD025552, 2016.

Carte, A. and Mossop, S.: Measurements of the concentration of atmospheric ice nuclei in Southern Africa, Bull. Obs. Puy de Dome, 4, 137-149, 1960.

Castro, A., Marcos, J., Dessens, J., Sánchez, J., and Fraile, R.: Concentration of ice nuclei in continental and maritime air masses in León (Spain), Atmos. Res., 47-48, 155-167, https://doi.org/10.1016/S0169-8095(98)00060-X, 1998.

Conen, F., Henne, S., Morris, C. E., and Alewell, C.: Atmospheric ice nucleators active $\geq-12{ }^{\circ} \mathrm{C}$ can be quantified on $\mathrm{PM}_{10}$ filters, Atmos. Meas. Tech., 5, 321-327, https://doi.org/10.5194/amt-5321-2012, 2012.

Cooper, W. A.: Ice Initiation in Natural Clouds. Precipitation Enhancement - A Scientific Challenge, Meteor. Monogr., Am. Meteor. Soc., Boston, MA, 21, 29-32, 1986.

DeMott, P., Sassen, K., Poellot, M., Baumgardner, D., Rogers, D., Brooks, S., Prenni, A., and Kreidenweis, S.: African dust aerosols as atmospheric ice nuclei, Geophys. Res. Lett., 30, 1732, https://doi.org/10.1029/2003GL017410, 2003.

DeMott, P. J., Prenni, A. J., Liu, X., Kreidenweis, S. M., Petters, M. D., Twohy, C. H., Richardson, M. S., Eidhammer, T., and Rogers, D. C.: Predicting global atmospheric ice nuclei distributions and their impacts on climate, P. Natl. Acad. Sci. USA, 107, 11217-11222, https://doi.org/10.1073/pnas.0910818107, 2010.

DeMott, P. J., Hill, T. C. J., McCluskey, C. S., Prather, K. A., Collins, D. B., Sullivan, R. C., Ruppel, M. J., Mason, R. H., Irish, V. E., Lee, T., Hwang, C., Rhee, T. S., Snider, J. R., McMeeking, G. R., Dhaniyala, S., Lewis, E. R., Wentzell, J. J. B., Abbatt, J., Lee, C., Sultana, C. M., Ault, A. P., Axson, J. L., Diaz Martinez, M., Venero, I., Santos-Figueroa, G., Stokes, M. D., Deane, G. B., Mayol-Bracero, O. L., Grassian, 
V. H., Bertram, T. H., Bertram, A. K., Moffett, B. F., and Franc, G. D.: Sea spray aerosol as a unique source of ice nucleating particles, P. Natl. Acad. Sci. USA, 113, 5797-5803, https://doi.org/10.1073/pnas.1514034112, 2016.

Fletcher, N.: The physics of rainclouds, Cambridge University Press, 1962.

Fomba, K. W., Müller, K., van Pinxteren, D., Poulain, L., van Pinxteren, M., and Herrmann, H.: Long-term chemical characterization of tropical and marine aerosols at the Cape Verde Atmospheric Observatory (CVAO) from 2007 to 2011, Atmos. Chem. Phys., 14, 8883-8904, https://doi.org/10.5194/acp-148883-2014, 2014.

Garimella, S., Kristensen, T. B., Ignatius, K., Welti, A., Voigtländer, J., Kulkarni, G. R., Sagan, F., Kok, G. L., Dorsey, J., Nichman, L., Rothenberg, D. A., Rösch, M., Kirchgäßner, A. C. R., Ladkin, R., Wex, H., Wilson, T. W., Ladino, L. A., Abbatt, J. P. D., Stetzer, O., Lohmann, U., Stratmann, F., and Cziczo, D. J.: The SPectrometer for Ice Nuclei (SPIN): an instrument to investigate ice nucleation, Atmos. Meas. Tech., 9, 2781-2795, https://doi.org/10.5194/amt-9-2781-2016, 2016.

Hallett, J. and Mossop, S.: Production of secondary ice particles during the riming process, Nature, 249, 26-28, 1974.

Heymsfield, A. and Willis, P.: Cloud conditions favoring secondary ice particle production in tropical maritime convection, J. Atmos. Sci., 71, 4500-4526, 2014.

Hobbs, P. and Locatelli, J.: Ice nucleus measurements at three sites in western Washington, J. Atmos. Sci., 27, 90-100, 1970.

Hobbs, P. and Rangno, A.: Ice Particle Concentration in Clouds, J. Atmos. Sci., 42, 2523-2549, 1985.

Hoffer, T. E. and Braham, R. R.: A Laboratory Study of Atmospheric Ice Particles, J. Atmos. Sci., 19, 232-235, 1962.

Isaac, G. A. and Douglas, R.: Frequency distributions of ice nucleus concentrations, J. Rech. Atmos., 5, 1-4, 1971.

Isono, K., Komabayasi, M., and Ono, A.: Volcanoes as a source of atmospheric ice nuclei, Nature, 183, 317-318, 1959.

Joly, M., Amato, P., Deguillaume, L., Monier, M., Hoose, C., and Delort, A.-M.: Quantification of ice nuclei active at near $0{ }^{\circ} \mathrm{C}$ temperatures in low-altitude clouds at the Puy de Dôme atmospheric station, Atmos. Chem. Phys., 14, 8185-8195, https://doi.org/10.5194/acp-14-8185-2014, 2014.

Jones, A., Thomson, D., Hort, M., and Devenish, B.: The UK Met Office's next generation atmospheric dispersion model, NAME III, Air Pollut. Model. Appl., XVII, 580-589, 2007.

Maruyama, H.: On the Annual Variation of Concentration and the Origin of Ice Nuclei in the Atmosphere, Papers in Meteor. and Geophys., XII, 216-246, 1961.

McCluskey, C., Hill, T., Malfatti, F., Sultana, C., Lee, C., Santander, M., Beall, C., Moore, K., Cornwell, G., Collins, D., Prather, K., Jayarathne, T., Stone, E., Azam, F., Kreidenweis, S., and DeMott, P.: A Dynamic Link between Ice Nucleating Particles Released in Nascent Sea Spray Aerosol and Oceanic Biological Activity during Two Mesocosm Experiments, J. Atmos. Sci., 74, 151166, https://doi.org/10.1175/JAS-D-16-0087.1, 2017.

McCluskey, C. S., DeMott, P. J., Prenni, A. J., Levin, E. J. T., McMeeking, G. R., Sullivan, A. P., Hill, T. C. J., Nakao, S., Carrico, C. M., and Kreidenweis, S. M.: Characteristics of atmospheric ice nucleating particles associated with biomass burning in the US: Prescribed burns and wildfires, J. Geophys. Res.-Atmos., 119, 10458-10470, https://doi.org/10.1002/2014JD021980, 2014.

Meyers, M., DeMott, P., and Cotton, W.: New Primary IceNucleation Parametrisation in an Explicit Cloud Model, J. Appl. Meteor., 31, 708-721, 1992.

Mossop, S. and Thorndike, N.: The use of membrane filters in measurements of ice nucleus concentration. I. Effect of sampled air volume, J. Appl. Meteorol., 5, 474-480, 1966.

Mossop, S., Ono, A., and Wishart, E.: Ice particles in maritime clouds near Tasmania, Q. J. Roy. Meteor. Soc., 96, 487-508, 1970.

Mossop, S. C.: The Origin and Concentration of Ice Crystals in Clouds, B. Am. Meteorol. Soc., 66, 264-273, 1985.

Murray, B. J., O'Sullivan, D., Atkinson, J. D., and Webb, M. E.: Ice nucleation by particles immersed in supercooled cloud droplets, Chem. Soc. Rev., 41, 6519-6554, https://doi.org/10.1039/C2CS35200A, 2012.

Ott, W.: A Physical Explanation of the Lognormality of Pollutant Concentrations, J. Air Waste Manag. Assoc., 40, 1378-1383, https://doi.org/10.1080/10473289.1990.10466789, 1990.

Pinti, V., Marcolli, C., Zobrist, B., Hoyle, C. R., and Peter, T.: Ice nucleation efficiency of clay minerals in the immersion mode, Atmos. Chem. Phys., 12, 5859-5878, https://doi.org/10.5194/acp-12-5859-2012, 2012.

Radke, L. F., Hobbs, P. V., and Pinnons, J. E.: Observations of Cloud Condensation Nuclei, Sodium-Containing Particles, Ice Nuclei and the Light-Scattering Coefficient Near Barrow, Alaska, J. Appl. Meteorol., 15, 982-995, https://doi.org/10.1175/15200450(1976)015<0982:OOCCNS>2.0.CO;2, 1976.

Rangno, A. and Hobbs, P.: Criteria for the Onset of Significant Concentrations of Ice Particles in Cumulus Clouds, Atmos. Res., 22, 1-13, https://doi.org/10.1016/0169-8095(88)90008-7, 1988.

Rangno, A. and Hobbs, P.: Ice particle concentrations and precipitation development in small polar maritime cumuliform clouds, Q. J. Roy. Meteorol. Soc., 117, 207-241, https://doi.org/10.1002/qj.49711749710, 1991.

Rangno, A. and Hobbs, P.: Ice particle concentrations and precipitation development in small continental cumuliform clouds, Q. J. Roy. Meteorol. Soc., 120, 573-601, https://doi.org/10.1002/qj.49712051705, 1994.

Rosenfeld, D., Yu, X., Liu, G., Xu, X., Zhu, Y., Yue, Z., Dai, J., Dong, Z., Dong, Y., and Peng, Y.: Glaciation temperatures of convective clouds ingesting desert dust, air pollution and smoke from forest fires, Geophys. Res. Lett., 38, L21804, https://doi.org/10.1029/2011GL049423, 2011.

Rosinski, J., Haagenson, P., Nagamoto, C., and Parungo, F.: Nature of ice-forming nuclei in marine air masses, J. Aerosol Sci., 18 , 291-309, 1987.

Schnell, R. and Vali, G.: Freezing nuclei in marine waters, Tellus, 27, 321-323, 1975.

Soulage, G.: Origins, Concentrations and Meteorological Importance of Atmospheric freezing nuclei, Nubila, 4, 43-67, 1961.

Stetzer, O., Baschek, B., Lüönd, F., and Lohmann, U.: The Zurich Ice Nucleation Chamber (ZINC) - A new instrument to investigate atmospheric ice formation, Aerosol Sci. Tech., 42, 64-74, 2008.

Sullivan, S. C., Hoose, C., Kiselev, A., Leisner, T., and Nenes, A.: Initiation of secondary ice production in clouds, Atmos. 
Chem. Phys., 18, 1593-1610, https://doi.org/10.5194/acp-181593-2018, 2018.

Vali, G.: Quantitative Evaluation of Experimental Results on the Heterogeneous Freezing Nucleation of Supercooled Liquids, J. Atmos. Sci., 28, 402-409, https://doi.org/10.1175/15200469(1971)028<0402:QEOERA>2.0.CO;2, 1971.

Vergara-Temprado, J., Murray, B. J., Wilson, T. W., O’Sullivan, D., Browse, J., Pringle, K. J., Ardon-Dryer, K., Bertram, A. K., Burrows, S. M., Ceburnis, D., DeMott, P. J., Mason, R. H., O'Dowd, C. D., Rinaldi, M., and Carslaw, K. S.: Contribution of feldspar and marine organic aerosols to global ice nucleating particle concentrations, Atmos. Chem. Phys., 17, 3637-3658, https://doi.org/10.5194/acp-17-3637-2017, 2017.

Welti, A., Lüönd, F., Kanji, Z. A., Stetzer, O., and Lohmann, U.: Time dependence of immersion freezing: an experimental study on size selected kaolinite particles, Atmos. Chem. Phys., 12, 9893-9907, https://doi.org/10.5194/acp-12-9893-2012, 2012.
Welti, A., Müller, K., Fleming, Z. L., and Stratmann, F.: Time series of ice nuclei concentration at Cape Verde, PANGAEA, https://doi.org/10.1594/PANGAEA.887029, 2018.

Wilson, T., Ladino, L., Alpert, P., Breckels, M., Brooks, I., Browse, J., Burrows, S., Carslaw, K., Huffman, J., Judd, C., Kilthau, W., Mason, R., McFiggans, G., Miller, L., Najera, J., Polishchuk, E., Rae, S., Schiller, C., Meng, S., Vergara-Temprado, J., Whale, T., Wong, J., Wurl, O., Yakobi-Hancock, J., Abbatt, J., Aller, J., Bertram, A., Knopf, D., and Murray, B.: A marine biogenic source of atmospheric ice-nucleating particles, Nature, 525, 234 238, https://doi.org/10.1038/nature14986, 2015. 